\title{
Patient Education and Medication Adherence: A Quasi-Experimental Study in Tertiary Hospitals Southwestern Nigeria
}

\section{Ayodapo $\mathrm{AO}^{1 *}$, Shabi $\mathrm{OM}^{2}$, Agboola $\mathrm{SM}^{2}$, Monsudi $\mathrm{KF}^{3}$, Deji-Dada $\mathrm{OO}^{4}$ and Olukokun TA $^{2}$}

${ }^{1}$ Department of Family Medicine, University College Hospital, Ibadan, Oyo State, Nigeria

${ }^{2}$ Department of Family Medicine, Federal Teaching Hospital, Ido-Ekiti/Afe Babalola University, Ado-Ekiti, Nigeria

${ }^{3}$ Department of Ophthalmology, Federal Medical Centre, Birnin-Kebbi, Kebbi State, Nigeria

${ }^{4}$ Department of Family Medicine, Ekiti State University Teaching Hospital, Ado-Ekiti, Ekiti State, Nigeria

*Corresponding Author: Ayodapo AO, Department of Family Medicine, University College Hospital,

Ibadan, Oyo State, Nigeria.
Received: February 18, 2020

Published: May 11, 2020

(C) All rights are reserved by Ayodapo A0., et al.

\begin{abstract}
Background: Hypertension is a global health issue among the adult population with high morbidity and mortality rates. As the case detection rate of hypertension increases in adult Nigerians, achieving goal blood pressure (BP) control has become an important management challenge due to poor adherence to medication.

Objective: To determine the role of patient education in medication adherence amongst adult Nigerians with primary hypertension attending primary care clinic of tertiary hospitals in Ekiti State.

Methods: Quasi-experimental study was carried out in 580 adult patients (290 in intervention and 290 in control group) with primary hypertension who had been on treatment for at least 6 months. Relevant data were collected using interviewer administered semi-structured questionnaire. Participants in intervention group received education sessions about hypertension and medication adherence at every clinic visit in a structured and individualised format. The control group was routinely monitored.

Results: The difference in the mean knowledge score in the intervention group increased to a statistically significant level $(\mathrm{p}<$ 0.05 ), from $9.5 \pm 2.8$ to $10.9 \pm 3.0$. An increase of $8.7(p=0.000)$ in mean adherence score was found in the intervention group after the education sessions while a marginal difference of $0.2(p=0.059)$ was found in the control group. Mean knowledge score and adherence to medication of subjects in intervention group showed a significant increase compared to those of the control group. Knowledge, adherence status and blood pressure control were significantly different between the two groups $(\mathrm{p}<0.05)$ at the end of the study.

Conclusion: Good knowledge about hypertension as a result of clinician educating patients is linked to better medication adherence and ultimately improved BP control. Primary care Physicians will do well to educate hypertensive patients with a view to improving medication adherence in them.

Keywords: Medication Adherence; Patient Education; Blood Pressure; Intervention; Hypertension
\end{abstract}

\section{Introduction}

Hypertension is probably the most common chronic condition dealt with by primary care physicians and other health practitioners. Hypertension presents an overwhelming global challenge and ranks third among the leading cause of permanent life disability $[1,2]$. Hypertension is a chronic non-communicable disease that is being recognized as an emerging public health problem in the developing countries including Nigeria. Although hypertension is asymptomatic, it usually leads to severe health problems such as stroke, heart and kidney diseases or even death [3]. Hypertension is a major risk factor and a powerful predictor of cardiovascular morbidity and mortality with proven benefit after treatment [3]. Therefore, control of hypertension will protect against stroke, congestive cardiac failure and all other causes of mortality.
Studies worldwide, including Nigerian studies indicate that despite the availability of safe and effective medical therapy, over half of all hypertensive patients do not take any treatment $[4,5]$ and more than half of those on treatment have blood pressure over the $140 / 90 \mathrm{mmHg}$ threshold [4,5]. The primary focus of antihypertensive therapy is to achieve a goal BP of less than140/90 $\mathrm{mmHg}$ for the general population and less than 130/80 $\mathrm{mmHg}$ for special high-risk populations such as patients with diabetes mellitus, renal disease and adverse cardiovascular events such as myocardial infarction and stroke [6]. The magnitude of blood pressure (BP) control differs between the developing and developed countries. In Nigeria, BP control rates in adult patients range from $24.2 \%$ to $35.8 \%$ according to research studies [7-9]. These disparities are probably due to a milieu of limited healthcare facilities, widespread 
personal and family poverty, ignorance, poverty of knowledge and other diverse factors.

Blood pressure control is influenced by multiple factors [1013], some of which are related to patient factors. Amongst the patient related factors is adherence to antihypertensive medication. Adherence is defined conceptually as the degree to which patient conforms to treatment as prescribed by the physician. Several methods of measuring adherence to medication have been described, but there is no 'gold standard' for precise measurement of adherence. The World Health Organization (WHO) describes poor adherence as the most important cause of uncontrolled blood pressure and estimates that $50-70 \%$ of people do not take their antihypertensive medication as prescribed [13]. This could be as a result of inadequate information, education and poor communication skills. Most common is poor knowledge, understanding and perception of hypertension or when a complex antihypertensive drug regimen is prescribed.

Patient education is an integrated part of treatment and care especially for long-term care patients. Patient education (PE) is the process by which health professionals impart information to patients that will alter their health behaviours or improve their health status. It is defined by Adriaan Visser $[14,15]$ as "a planned learning experience using a combination of methods such as teaching, counselling and behaviour modification techniques which improve patients knowledge and influence health and illness behaviour". Few studies have suggested patient education as a useful tool to be taken seriously in managing people with hypertension [16-18].

\section{Aim of the Study}

This study aim to research on patient education and adherence to medication amongst adult Nigerians with primary hypertension attending primary care clinic of tertiary hospitals in Ekiti State.

\section{Method}

Design

This was a clinic-based quasi-experimental controlled study with pre-intervention, intervention and post-intervention design carried out on 560 patients over a 4 month period at the department of family medicine of FMC Ido-Ekiti and EKSUTH Ado-Ekiti, which are the tertiary hospitals in Ekiti State, Western Nigeria.

\section{Setting}

The department of Family Medicine serves as a primary care clinic within these hospitals. All adult patients, excluding those who need emergency healthcare services, paediatric patients and antenatal women, are first seen at the Department of Family Medicine. Patients who need primary care are managed and followed up in the clinic, whilst those that need specialist clinics were referred. The clinic is run by consultant Family Physicians and postgraduate resident doctors in Family Medicine.

\section{Inclusion and exclusion criteria}

The inclusion criteria were adult hypertensive patients aged $\geq$ 18 years who gave informed consent and had been on outpatient treatment for hypertension in the clinic for at least 6 months. Exclusion criteria included critically ill patients, those with an established cause of hypertension, special high-risk populations, such as hypertensive patients with diabetes mellitus, renal disease and previous adverse cardiovascular events such as myocardial infarction and stroke.

Sampling

Using the formula for estimating proportions in a quasi-experimental design:

$$
\mathrm{n}=\left(2\left(\mathrm{Z}_{\alpha}+\mathrm{Z}_{\beta}\right) \mathrm{pq}\right) / \mathrm{d}^{2}
$$

Where $\mathrm{n}$ is the sample size per group.

An adequate and reliable minimum sample size was determined to be 263.2 per group, using the prevalence of work done in the south western Nigeria (Oshogbo), which was 13.6\% [19].

Sample size of 290 adult hypertensive patients each were recruited in the intervention and control group to allow for patients that will drop out of the study.

\section{Sampling technique}

Selection of respondents: Simple random sampling technique was used:

- $\quad$ Step 1: Lists of all eligible participants was made from the clinic register.

- $\quad$ Step 2: Each eligible participant was assigned numbers. The coding of the numbers assigned depended on the number of digits in the calculated sample size. Since the sample size $n=290$, the numbers assigned was three digits, from 001.

- Step 3: A table of random numbers was generated from the computer. The table consist of randomly computed numbers that were arranged in rows and columns. The table was constructed in a way that every digit occurs with approximately equal probability.

- $\quad$ Step 4: A starting point was selected by blindly putting a pencil on a number in the random number table and started from that number down the columns of the table. At the end of a randomly selected column, the next column is read and the one after until the sample size $n=290$ were attained. Numbers greater than the sampling frame and a duplicated number was ignored.

Selection of controls: The simple random sampling process outlined above was replicated among hypertensives attending family medicine clinic at Ekiti State University Teaching Hospital, AdoEkiti to select 290 eligible participants who served as control. 
The controls were only matched for socio-demographic characteristics. The matching was achieved by subjecting the two groups to statistical analysis which shows the difference between the two groups was not statistically significant.

\section{Data collection methods}

Data collection was through the use of a self-designed, pretested, semi-structured questionnaire. The questionnaire had four sections namely: socio-demographic, knowledge, adherence and the clinical data section. Knowledge of respondents was assessed using Hypertension Fact Questionnaire (HFQ), a 15-item questions with a high reliability and validity (Cronbach $\alpha=0.70$ ) [20]. The questions assess the knowledge of patients about hypertension, the causes, treatment and management [20]. Each response was scored as 'yes', 'no' or 'do not know'. Knowledge was assessed by giving 1 to correct answer and 0 to the wrong answer. The "don't know" response was also taken as 0 . HFQ scoring ranges from 15 (maximum) to 0 (minimum). Knowledge scores for individuals were calculated and summed up to give the total knowledge score for each group.

Adherence was determined using Morisky Medication Adherence Scale (MMAS-4), a 4-item self-report scale developed by Morisky., et al. with a high reliability and validity (Cronbach $\alpha=$ 0.61) [21], which has been particularly useful in chronic conditions such as hypertension. ${ }^{1}$ It measures both intentional and unintentional adherence based on forgetfulness, carelessness, stopping medication when feeling better and stopping medication when feeling worse. The advantages of this over other methods of measurement include its simplicity, speed, cheap and validity of use [22]. The total score for MMAS-4 was $100 \%$. A cut off level of $\geq 80 \%$ was considered adherent while respondents having $<80 \%$ score was non-adherent.

Five research assistants who are a resident doctor, a nurse and three information officers were used. The research assistants were recruited and trained by the investigator for two days for the purpose of data collection, viz-a-viz informed consent process, administering of questionnaire and accurate clinical data measurement. Pre- and post-training evaluation was done by the researcher to ensure adequate knowledge of this study and competence in the collection of required data. The information officers assisted the investigator in the administering of questionnaires to the respondents. Literate participants were allowed to complete a questionnaire on their own with the assistance from the interviewer. The investigator gave the respondents the education on hypertension. The investigator alongside with the resident doctor and the nurse took the BP of the respondents. Blood pressure was measured using an appropriate cuff-sized Accosson ${ }^{\star}$ mercury sphygmomanometer and stethoscope. BP readings were based on the seventh report of the Joint National Committee on Prevention, Detection, Evaluation, and Treatment of High Blood Pressure classification and guidelines [13].

\section{Protocols}

Pre-intervention activities: A baseline survey of the study population to determine the knowledge regarding hypertension and adherence to medication was conducted using the pre-tested questionnaire. Respondent clinical parameters- blood pressure, weight and height was measured and body mass index (BMI) calculated. The pre-intervention (baseline) data collection were collected from both the intervention and control groups.

Intervention activities: The patient education intervention included, educating respondents in the intervention group on what hypertension is, its risk factors, complications and treatment with emphasis on adherence to medications. This was started upon recruitment at first (baseline) visit and at follow-up clinic visits. The investigator had 2 contacts with each respondent in the intervention group within the study period for reinforcement. Each contact session lasted about 30 - 45 minutes. Each session started with an open-ended interrogative communication using local language. The investigator provided clear and thorough information and adequate time was allowed for respondents questions. In order to ensure the availability of respondents for post intervention activities, respondents phone numbers and contact addresses were taken for a follow up information regarding post-intervention activities.

Hypertensives accessing care in family medicine department in FMC Ido-Ekiti were the intervention group. The control group were hypertensives accessing care in family medicine department, EKSUTH Ado-Ekiti.

Post-intervention activities: The post-intervention data collection was carried out in both the intervention and control groups 4 months after the intervention. The same instrument of data collection used at baseline was used for post-intervention data collection. Data was collected using questionnaire and measurement of the respondent clinical parameters-blood pressure, weight and height. However, for the benefits of the respondents of the control group and for ethical consideration, the control group was also provided with similar education at the end of the study.

\section{Data analysis}

All data collected was analysed, after being sorted out and coded serially, using the statistical Package for social sciences (SSPS) for windows software version 16.0. Frequency tables and diagrams in form of graphs and charts were generated for relevant variables. Mean, mode, median, standard deviations, proportion and percentage was determined as appropriate. The mean and standard deviation (SD) were calculated for continuous variables while categorical variables were summarized using proportions. Test of significance was done using Pearson's Chi-Square and Student's t-test as appropriate. Chi square was used to determine statistical significance of observed differences in cross-tabulated variables. The student t-test was used to compare the means when there were only 2 means to compare. P-value of equal or less than 0.05 was taken to be statistically significant. Two stage analysis was done, analysis of the pre-intervention and post-intervention questionnaire. 


\section{Ethical consideration}

Ethical approval was obtained from the two hospitals, Federal Medical Center (FMC), Ido-Ekiti and Ekiti State University Teaching Hospital (EKSUTH), Ado-Ekiti. Informed written consent was also obtained from the respondents.

\section{Results}

The socio-demographic profile of the respondents showed that majority were in the age group of 46 to 75 years, with the modal age group being 56 - 65 years and a female preponderance in both groups. The mean age of the hypertensive patients in this study was $61.9 \pm 10.1$ years and $61.5 \pm 10.5$ years in the intervention and control group respectively. The age group distribution revealed a pattern of increasing numbers of subjects with age, with a maximum number at age group 56 - 65 years $(32.4 \%)$ in the intervention group and age group $66-75$ years $(32.1 \%)$ in the control group. Table 1 showed that the socio-demographic characteristics of the intervention and control group were similar. There was no statistically significant difference in all the variables.

Figure 1 showed an increase in the hypertension knowledge mean scores from 9.5 to 10.9 in the intervention group while the control group increases from 9.6 to 9.7 .

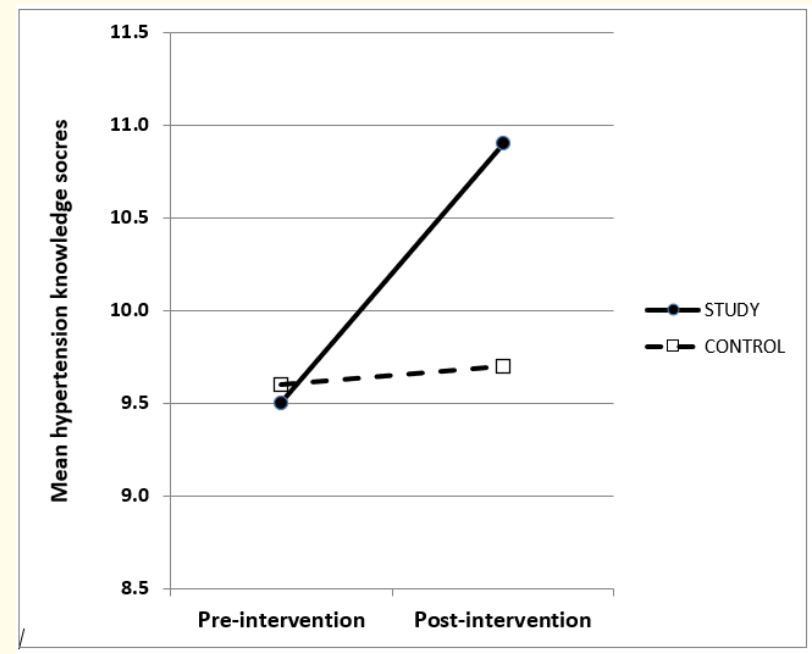

Figure 1: Mean knowledge scores by intervention/ study and control group.

Figure 2 showed an increase in medication adherence score amongst the intervention group while there is a marginal increase in the control group.

The rate of decrease in the systolic blood pressure (SBP) and diastolic blood pressure (DBP) was more in the intervention group than in the control group (Figure 3 and 4).

In table 2, the difference in the mean score of knowledge of hypertension ( $9.5 \pm 2.8$ to $10.9 \pm 3.0$ ), medication adherence (77.8 \pm 11.7 to $86.5 \pm 11.9$ ), and blood pressure (SBP $151.7 \pm 11.2$ to 145.7 \pm 19.1, DBP $88.2 \pm 9.9$ to $81.1 \pm 10.4$ ) pre and post-intervention were statistically significant among the intervention group.

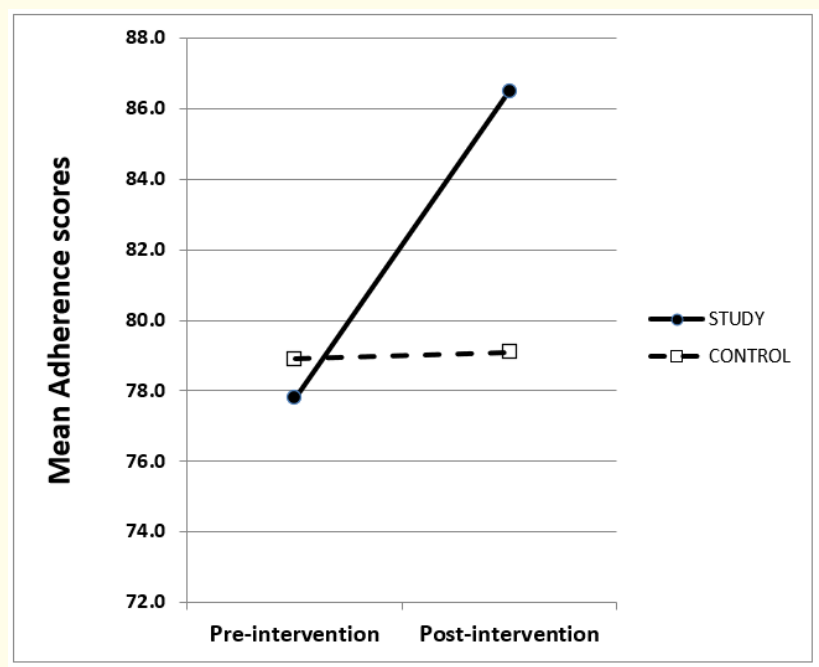

Figure 2: Mean Adherence score by intervention/ study and control group.

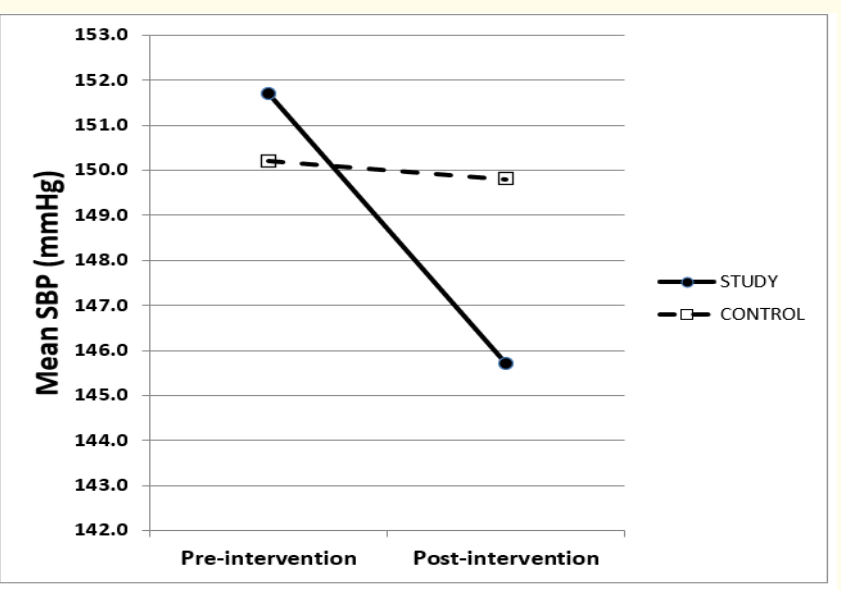

Figure 3: Mean systolic blood pressure (SBP) by intervention/study and control group.

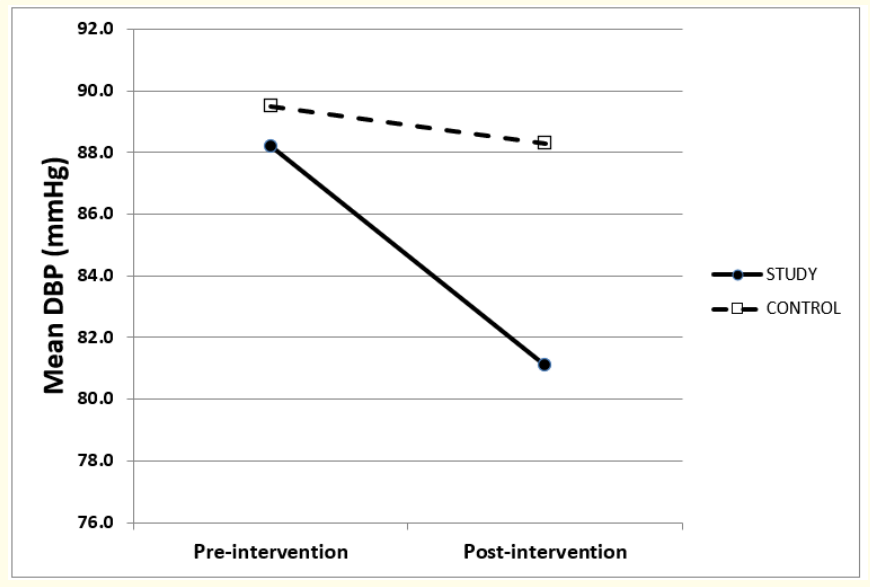

Figure 4: Mean diastolic blood pressure by intervention/study and control group. 


\begin{tabular}{|c|c|c|c|c|c|}
\hline \multirow{3}{*}{ Variables } & \multicolumn{2}{|c|}{ Subject category } & \multirow{3}{*}{$x^{2}$} & \multirow{3}{*}{ df } & \multirow{3}{*}{$P$ value } \\
\hline & Intervention $(n=290)$ & Control $(n=290)$ & & & \\
\hline & n (\%) & n (\%) & & & \\
\hline \multicolumn{6}{|l|}{ Gender } \\
\hline Male & $102(35.2)$ & $98(33.8)$ & $0.069 *$ & 1 & 0.793 \\
\hline Female & $188(64.8)$ & $192(66.2)$ & & & \\
\hline \multicolumn{6}{|l|}{ Age (yrs) } \\
\hline $36-45$ & $27(9.3)$ & $22(7.6)$ & & & \\
\hline $46-55$ & $67(23.1)$ & $70(24.1)$ & & & \\
\hline $56-65$ & $94(32.4)$ & $88(30.3)$ & 2.022 & 4 & 0.732 \\
\hline $66-75$ & $81(27.9)$ & $93(32.1)$ & & & \\
\hline $76+$ & $21(7.2)$ & $17(5.9)$ & & & \\
\hline \multicolumn{6}{|l|}{ Ethnicity } \\
\hline Yoruba & $279(96.2)$ & $284(97.9)$ & & & \\
\hline Ibo & $9(3.1)$ & $6(2.1)$ & 2.644 & 2 & 0.267 \\
\hline Others & $2(0.7)$ & $0(0.0)$ & & & \\
\hline \multicolumn{6}{|l|}{ Domicile } \\
\hline Urban Ekiti & $124(42.8)$ & $134(46.2)$ & & & \\
\hline Rural Ekiti & $161(55.4)$ & $154(53.1)$ & 1.829 & 2 & 0.401 \\
\hline Outside Ekiti & $5(1.8)$ & $2(0.7)$ & & & \\
\hline \multicolumn{6}{|l|}{ Marital Status } \\
\hline Single & $3(1.0)$ & $6(2.1)$ & & & \\
\hline Married & $252(86.9)$ & $248(85.5)$ & 2.290 & 3 & 0.514 \\
\hline Separated & $6(2.1)$ & $3(1.0)$ & & & \\
\hline Widowed & $29(10.0)$ & $33(11.4)$ & & & \\
\hline \multicolumn{6}{|l|}{ Religion } \\
\hline Christianity & $257(88.6)$ & $249(85.9)$ & & & \\
\hline Islam & $32(11.0)$ & 37 (12.8) & 2.289 & 2 & 0.318 \\
\hline \multirow[t]{2}{*}{ Traditional } & $1(0.3)$ & $4(1.4)$ & & & \\
\hline & n (\%) & n (\%) & & & \\
\hline \multicolumn{6}{|l|}{ Type of Family } \\
\hline Monogamy & $214(73.8)$ & $206(71.0)$ & $0.423^{*}$ & 1 & 0.515 \\
\hline Polygamy & $76(26.2)$ & $84(29.0)$ & & & \\
\hline \multicolumn{6}{|l|}{ Family Size } \\
\hline Less than 5 & $27(9.3)$ & 34 (11.7) & 1.291 & 2 & 0.524 \\
\hline $5-9$ & $228(78.6)$ & $217(71.4)$ & & & \\
\hline 10 or More & $35(12.1)$ & $39(13.4)$ & & & \\
\hline \multicolumn{6}{|c|}{ Number of Dependants } \\
\hline Less than 5 & $220(75.9)$ & $207(71.4)$ & $1.278^{*}$ & 1 & 0.258 \\
\hline 5 or More & $70(24.1)$ & $83(28.6)$ & & & \\
\hline \multicolumn{6}{|l|}{ Educational level } \\
\hline None & $58(20.0)$ & $61(21.0)$ & & & \\
\hline Primary & $55(19.0)$ & $58(20.0)$ & & & \\
\hline Secondary & $33(11.4)$ & $37(12.8)$ & 1.098 & 4 & 0.895 \\
\hline Tertiary & $119(41.0)$ & $107(36.9)$ & & & \\
\hline Postgraduate & $25(8.6)$ & $27(9.3)$ & & & \\
\hline \multicolumn{6}{|l|}{ Social class $^{\mathrm{a}}$} \\
\hline Class I & $12(4.1)$ & $9(3.1)$ & & & \\
\hline Class II & $56(19.3)$ & $67(23.1)$ & & & \\
\hline Class III & $83(28.6)$ & $81(27.9)$ & 4.005 & 4 & 0.401 \\
\hline Class IV & $133(45.9)$ & $121(41.7)$ & & & \\
\hline Class V & $6(2.1)$ & $12(4.1)$ & & & \\
\hline \multicolumn{6}{|l|}{ Income level (NGN) } \\
\hline High & $35(12.1)$ & $47(16.2)$ & & & \\
\hline Middle & $148(51.0)$ & $138(47.6)$ & 2.125 & 2 & 0.346 \\
\hline Low & $107(36.9)$ & $105(36.2)$ & & & \\
\hline
\end{tabular}

Table 1: Socio-demographic distribution of intervention and control group.

*: Yate's correction applied. a: Oyedeji GA. Socioeconomic and cultural background of hospitalized children in Ilesha. Nigerian Journal of Paediatrics 1985; 12: 111-117. 


\begin{tabular}{|c|c|c|c|c|}
\hline \multirow[t]{2}{*}{ Variables } & \multicolumn{2}{|c|}{ Intervention } & \multicolumn{2}{|c|}{ Control } \\
\hline & Pre-intervention & Post-intervention & Pre-intervention & Post-intervention \\
\hline \multicolumn{5}{|l|}{ Knowledge Scores } \\
\hline \multirow[t]{2}{*}{ Mean \pm SD } & $9.5 \pm 2.8$ & $10.9 \pm 3.0$ & $9.6 \pm 3.3$ & $9.7 \pm 3.5$ \\
\hline & $\mathrm{P}=0.000^{*}$ & & $P=0.157$ & \\
\hline \multicolumn{5}{|l|}{ Adherence Score } \\
\hline \multirow[t]{2}{*}{ Mean \pm SD } & $77.8 \pm 11.7$ & $86.5 \pm 11.9$ & $78.9 \pm 16.1$ & $79.1 \pm 16.7$ \\
\hline & $\mathrm{P}=0.000^{*}$ & & $P=0.059$ & \\
\hline \multicolumn{5}{|l|}{ Blood Pressure } \\
\hline \multirow[t]{2}{*}{ Mean SBP (mmHg) } & $151.7 \pm 11.2$ & $145.7 \pm 19.1$ & $150.2 \pm 13.2$ & $149.8 \pm 22.7$ \\
\hline & $P=0.000$ & & $P=0.000$ & \\
\hline \multirow[t]{2}{*}{ Mean DBP (mmHg) } & $88.2 \pm 9.9$ & $81.1 \pm 10.4$ & $89.5 \pm 10.4$ & $88.3 \pm 12.9$ \\
\hline & $P=0.000$ & & $P=0.070$ & \\
\hline
\end{tabular}

Table 2: Effect of patient education on knowledge, medication adherence and blood pressure control.

*Related samples Wilcoxon signed rank test used for differences between Intervention and Control groups.

\section{Discussion}

The mean age of the hypertensive patients in this study was $61.9 \pm 10.1$ years and $61.5 \pm 10.5$ years in the intervention and control group respectively. The mean age in this study was higher than $52 \pm 7.4$ years reported by Iloh., et al. [6] $53.36 \pm 11.14$ years by Kabir., et al. [23] and $50.34 \pm 11.14$ years by Akpa., et al [24]. This difference may be due to health behaviour pattern of our patients. In this study, 67.5\% (196) of the intervention group and $68.3 \%$ (198) of the control group were aged 55 years and above. This pattern of increasing number of subjects with age found in this study was similar to reports from other studies $[6,25]$. This is consistent with the fact that the prevalence of hypertension increases with age in most populations, and the prevalence is highest in individuals over the age of fifty $[23,26,27]$. In many populations, there is a higher prevalence of hypertension in females than in males $[24,26,27]$. In this study, $64.8 \%$ of the intervention group and $66.2 \%$ of the control group were females. This is not far from $60 \%$ and $70 \%$ reported at Umuahia and Turkey $[6,28]$. There was a slight female predominance in both groups in this study (male: female = 1:1.7 to 1.9), as also reported by Iloh., et al [6]. The difference in sex ratio of hypertensives may be associated with the differences in the relative frequency of obesity and physical inactivity among the sexes $[29,30]$.

The pre-intervention overall mean knowledge score of respondents was $9.7 \pm 4.3$. This score is higher than $8.03 \pm 0.42$ found in a cross-sectional study where same instrument was used to assess knowledge of hypertensives above 18 years, in the outpatient department of two tertiary public hospitals by Saleem., et al. in Quetta, Pakistan [20]. The difference may be due to the fact that, our respondents are better income earners with some formal education and have access to health facilities. Both intervention group and the control group in our study had mean knowledge score of $9.5 \pm$ 2.8 and $9.6 \pm 3.3$ respectively. Though there was a marginal difference in the mean knowledge score of both groups, the difference was not statistically significant. However, at post-intervention, there was a significant difference in the mean knowledge score of both groups. The difference is as a result of teaching, counselling and behaviour modification sessions which improve the intervention group's knowledge. Right knowledge about hypertension and its treatment creates a clear understanding and avoids confusion about the treatment and the disease condition.

The overall mean adherence score was $82.8 \pm 14.9$. This was higher than the mean score of $62.5 \pm 13$ found in a cross sectional study that use similar instrument in measuring adherence among the Pakistani hypertensives by Hashmi., et al [1]. The higher mean score may be associated with a better socio-economic status in this study population as against the Pakistani study. Also, patients with co-existing medical conditions were included in the Pakistani study. In our study, the mean adherence score in both groups was similar at pre-intervention as the marginal difference observed was not statistically significant. However, at post-intervention, there was a statistically significant difference in the mean adherence score. Mean adherence score increased from $77.8 \pm 11.7$ to $86.5 \pm 11.9$ in the intervention group, while a marginal increase of 0.2 was found in the control group. The mean adherence score improves to a statistically significant level as the patient knowledge improves via teaching sessions among the intervention group. Patient education enhances the knowledge about hypertension resulting in better adherence to medication. A number of studies support such an association in which a positive relationship was found between knowledge and adherence [20,31-33].

In our study, the mean SBP and DBP in both groups were similar at pre-intervention. The differences observed were not statistically significant. However, at post-intervention, the reductions found in mean SBP (6.0) and DBP (7.1) among the intervention group was statistically significant, an outcome of education intervention. Compared to interventional study carried out in Lagos by Busari., et al. [25] the effective blood pressure control remarkably increased to $86.04 \%$. Our result is also comparable to a study by Iloh., et al. among hypertensives in Umuahia [6]. They also reported a significantly higher blood pressure control in those that adhered to an- 
tihypertensive medication compared with non-adherent patients. Similar findings were reported in a number of studies $[25,32,34$ 36].

The findings of our study have demonstrated the contribution of patient education to medication adherence and blood pressure control amongst the intervention group of the study population. Many of the respondents in the intervention group had better knowledge of hypertension, adherence to medication and blood pressure control.

\section{Conclusion}

Educational intervention program in this study among the intervention group of hypertensive patients had a positive impact on the knowledge of hypertension, adherence to medications and ultimately resulted in a better blood pressure control. Physicians should educate their hypertensive patient with a view to improve drug adherence and achieve a target BP. This study only controlled for socio-demographic characteristics, but not for other variables that can affect medication adherence. Short-term assessment of patient education is also a limitation of this study. Longitudinal studies that examine the patient education and medication adherence trajectory over time would be more informative. Self-reporting used as the only method of measuring adherence has the disadvantage of recall bias and eliciting only socially acceptable response and hence may overestimate the level of adherence. Further research need to be conducted using randomised controlled trial where some other extraneous variables or factors affecting adherence to medication like choice of medication, distance to the centre, family support etc., will be controlled for.

\section{Bibliography}

1. Saman KH., et al. "Factors associated with adherence to antihypertensive treatment in Parkistans". PLoS One 2.3 (2007): e280.

2. Kearney PM., et al. "Global burden of hypertension: analysis of worldwide data". Lancet 365 (2005): 217-223.

3. Uzun S., et al. "The assessment of adherence of hypertensive individuals to treatment and lifestyle change recommendations". Anadolu Kardiyol Derg 9 (2009): 102-109.

4. Inkster ME., et al. "Adherence to antihypertensive medication and association with patient and practice factors". Journal of Human Hypertension 20 (2006): 295-297.

5. Falaschetti E. "Blood pressure". Health Survey for England (2004): 181-220.

6. Iloh GUP., et al. "Medication adherence and blood pressure control amongst adults with primary hypertension attending a tertiary hospital primary care clinic in Eastern Nigeria". African Journal of Primary Health Care and Family Medicine 5.1 (2013): 123-126.
7. Omuemu VO., et al. "Awareness of high blood pressure status, treatment and control in a rural community in Edo State". $\mathrm{Ni}$ gerian Journal of Clinical Practice 10 (2007): 208-212.

8. Katibi IA., et al. "Knowledge and practice of hypertensive patients as seen in a tertiary hospital in the middle belt of Nigeria”. Nigerian Journal of Clinical Practice 13 (2010): 159-162.

9. Sani MU., et al. "Blood pressure control among treated hypertensives in a tertiary health institution". Nigerian Journal of Clinical Practice 17 (2008): 270-274.

10. Maiyaki MB and Garbati MA. "The burden of non-communicable diseases in Nigeria in the context of globalization". Annals of African Medicine 13.1 (2014): 1-10.

11. Adebisi 00 and Samali A. "Poverty and hypertension in Nigerian adults: A barrier to its control and treatment. A review". Unique Research Journal of Medical Sciences 1.3 (2013): 14-20.

12. Ganiyu KA and Suleiman IA. "Economic burden of drug therapy in hypertension management in a private Teaching Hospital in Nigeria". British Journal of Pharmaceutical Research 4.1 (2014): 70-78.

13. Chobanian AU., et al. "Seventh Report of the Joint National Committee on Prevention, Detection, Evaluation and Treatment of High Blood Pressure". Journal of the American Medical Association 289 (2003): 2560-2572.

14. Visser A., et al. "Patient education and counseling Editorial". Patient Education and Counseling 72.3 (2008): 357-358.

15. Hamers JP., et al. "Editorial. Changing patient education". Patient Education and Counseling 78.3 (2010): 273-274.

16. Busari OA., et al. "Impact of patients' knowledge, attitude and practices on Hypertension on Compliance with Antihypertensive drugs in a Resource-poor setting". TAV Preventive Medicine Bulletin 9.2 (2010): 87-92.

17. Ahaneku GI., et al. "Evaluation of blood pressure and indices of Obesity in a typical rural community in eastern Nigeria". Annals of African Medicine 10 (2011): 120-126.

18. Hacihasaoglu R and Gozum S. "The effect of patient education and home monitoring on medication compliance, hypertension, management, healthy lifestyle behaviours and BMI in a primary health care setting". Journal of Clinical Nursing 20.5-6 (2011): 692-705.

19. Asekun-Olarinmoye EO., et al. "Prevalence of hypertension in the rural adult population of Osun State, southwestern Nigeria”. International Journal of General Medicine 6 (2013): 317322. 
20. Saleem F., et al. "Association between Knowledge and Drug adherence in patients with Hypertension in Quetta, Pakistan". Tropical Journal of Pharmaceutical Research 10.2 (2011): 125132.

21. Morisky DE., et al. "Concurrent and predictive validity of a self-reported measure of medication adherence". Medical Care 24.1 (1986): 67-74.

22. Amal S., et al. "Hospital admission and poor adherence to antihypertensive therapy: Is there any relationship? " Int Journal of Pharmacy and Pharmaceutical Sciences 2.1 (2009): 38-46.

23. Kabir M., et al. "Compliance to medication among hypertensive patients in Murtala Mohammed Specialist Hospital, Kano, Nigeria". Journal of Community Medicine and Primary Health Care 16.1 (2004): 16-20.

24. Akpa MR., et al. "Drug compliance among hypertensive patients in Port Harcourt, Nigeria”. Nigerian Journal of Medicine 14 (2005): 55-57.

25. Busari A., et al. "Educational Intervention as a Strategy for Improving Blood Pressure Status of market Women in Lagos, Nigeria". The Internet Journal of Health 11.1 (2010).

26. Ogah SO., et al. "Blood pressure, prevalence of hypertension and hypertension related complications in Nigerian Africans: A review". World Journal of Cardiology 4.12 (2012): 327-340.

27. Ordinioha B. "The prevalence of hypertension and its modifiable risk factors among lecturers of a medical school in Port Harcourt, south-south Nigeria: Implications for control effort”. Nigerian Journal of Clinical Practice 16.1 (2013): 1-4.

28. Karaeren H., et al. "The effect of the content of the knowledge on adherence to medication in hypertensive patients". Anadolu Kardiyol Derg 9 (2009): 183-188.

29. Reckelhoff JF. "Gender Differences in the Regulation of Blood Pressure". Hypertension 37 (2001): 1199-1208.

30. Shawand BH and Protheroe CL. "Sex, drugs and blood pressure control: the impact of age and gender on sympathetic regulation of arterial pressure". The Journal of Physiology 590.12 (2012): 2841-2843.

31. Ambaw DA., et al. "Adherence to antihypertensive treatment and associated factors among patients on follow up at University of Gondor Hospital, Northwest Ethiopia". BMC Public Health 12 (2012): 282.

32. Almas A., et al. "Good knowledge about hypertension is linked to better control of hypertension A multicentre cross sectional study in Karachi, Pakistan”. BMC Research Notes 5 (2012): 579.

33. Kim EY., et al. "Does knowledge matter? Intentional medication non-adherence among middle-aged Korean Americans with high blood pressure". Journal of Cardiovascular Nursing 22.5 (2007): 397-404.
34. Casson RI., et al. "Markers of loss of control of hypertension". Canadian Family Physician 49 (2003): 1323-1331.

35. Morris AB., et al. "Factors associated with drug adherence and blood pressure control in patients with hypertension". Pharmacotherapy 26.4 (2006): 483-492.

36. DiMatteo MR., et al. "Patient adherence and medical treatment outcomes: a meta-analysis”. Medical Care 40.9 (2002): 794811.

\section{Assets from publication with us}

- Prompt Acknowledgement after receiving the article

- Thorough Double blinded peer review

- Rapid Publication

- Issue of Publication Certificate

- High visibility of your Published work

Website: https://www.actascientific.com/

Submit Article: https://www.actascientific.com/submission.php Email us: editor@actascientific.com

Contact us: +919182824667 